\title{
Does Financial Education Matter? Examining Financial Literacy among Students of Economics and Finance
}

\author{
PhD.Dajana Barbić \\ Faculty of Economics and Business, University of Zagreb
}

\begin{abstract}
According to the findings of the previous studies, many students have problems managing their personal finances. One of the major issues among university students concerns their financial behaviour, especially their spending habits and cash management skills. Financial literacy tests around the world indicate that many young people have poor financial knowledge and skills. Research suggests that financial education has an important impact on students' financial literacy and financial behaviour. Therefore, the aim of this study is i) firstly, to assess the level of financial knowledge, financial attitude and financial behaviour among financially educated students; ii) secondly, to make relevant comparison based on type of student's financial education; iii) thirdly, to evaluate an overall score of financial literacy among financially educated students; iv) finally, to provide some conclusions and policy implications concerning financial literacy. All respondents are students of economics and finance. To measure the impact of the type of financial education on financial literacy and financial behaviour, three months long personal finance course was organized and half of the respondents took part in the course while the other part did not participate in the course. By assessing financial literacy of both student groups, it is possible to get some insight into the financial habits and behaviour of those who received general financial education and those who received both, general and specific personal finance education.
\end{abstract}

Keywords: economics; finance; financial behavior; financial education; financial literacy; students 